У,

ББК 67.405 .1

DOI 10.22394/1682-2358-2018-5-144-152

A.A. Ivanov, Candidate of Sciences (Law), senior lecturer of the Labor Law Department, Saratov State Academy of Law

\section{THE LEGAL STATUS OF HIV-POSITIVE CITIZENS \\ IN THE FIELD \\ OF LABOR THROUGH \\ THE PRISM \\ OF SOCIALLY SIGNIFICANT DISEASES}

The legal status of HIV-positive citizens in the context of labor relations in terms of socially significant diseases is examined. Russian and foreign regulations and international documents that provide for the legal status of these persons in the field of labor are analyzed. Special attention is paid to the phenomenon of discriminatory dismissal and the order of the employer's actions.

Key words and word-combinations: discriminatory restrictions, foreign experience in regulating the work of HIV-infected and AIDS patients.
А.А. ИВаноб, кандидат юридиеских наук, стариий преподаватель кафедрь трудового права Саратовской государственной юридической академии (email: artiom-depeche@yandex.ru)

\section{ПРАВОВОЕ ПО ОЖЕНИЕ ВИЧ-ИНФИЦИРОВАННЫХ ГРАЖААН В СФЕРЕ ТРУАА ЧЕРЕЗ ПРИЗМУ СОЦИААЬНО ЗНАЧИМЫХ ЗАБОАЕВАНИЙ}

Аннотация. Исследуется правовое положение ВИЧ-инфицированных граждан в контексте трудовых правоотношений с точки зрения социально значимых заболеваний. Анализируются российские и зарубежные нормативно-правовые акты, международные документы, предусматривающие правовой статус данных лиц в сфере труда. Особое внимание обращается на явление дискриминационного увольнения и действия работодателя в подобных ситуациях.

Ключевые слова и словосочетания: дискримнационные ограничения, зарубежный опыт регулирования труда ВИЧ-инфицированных и больных СПИДом.

B $\mathrm{B}_{\mathrm{up}}$ не явмяется болезнью АавподтвержАается соџиологическими исслеАованиями позАнего советского периода [1, с. 83]. Согласно Аанным Российского федерамьного центра по профимактике и борьбе с ВИЧ / СПИА, в России с 1987 г. зарегистрированы более 318 тыс. человек ВИЧ / СПИА-инфицированных. ОАнако 
большинство экспертов считают, что реальное число мюдей с ВИЧ в России гораздо выше - от 200 тыс. человек (по данным федерального центра) до 1,5 млн человек (по данным Национального разведывательного совета США), что соответствует $1-2 \%$ взрослого поколения.

За 2018 г., по сведениям Федеральной службы по надзору в сфере защиты прав потребитемей и благополучия чемовека, зафиксированы 42662 новых случая болезни, вызванной вирусом иммунодефиџита человека (в эту статистику также входят миџа от 14 до 17 мет) [2]. По Аанным Федеральной службы государственной статистики, мидерами по выявленным случаям заражения ВИЧ / СПИА являются Кемеровская, Новосибирская, Иркутская, Свердмовская, Самарская, Челябинская, Московская области, Пермский, Краснодарский край, Республика Башкортостан, среди городов - Москва, Санкт-Петербург [3] .

Исходя из приведенных статистически данных, можно сдекать однозначный вывоА, что данное заболевание встречается не только у представителей социальных низов общества. Среди инфицированных немало граждан, которые в принџипе не входят в группу риска и обцадают профессиональными качествами, весьма востребованными на рынке труда. При этом около $80 \%$ ВИЧ-инфиџированных россиян моложе тридџати мет $[4$, с. 2] .

Отметим, что наличие ВИЧ / СПИА имеет не только медицинские посмедствия, но объективно порождает иные соџиальные сложности, межащие в плоскости человеческой психологии и права. Общество меняет отношение к такому гражданину и чаще всего рассматривает его как носителя нежелательного качества [5]. Это, в свою очередь, связано с практикой дискриминации ВИЧ-инфиџированных, стигматизаџии их соџиального, и в том числе правового статуса [6, с. 160]. Информационные и психологические причины такого положения дел достаточно ясны - недостаточное понимание характера бомезни, мифы и безответственные сообшения СМИ («болезнь наркоманов» и т.А.), страх и преАрассудки [7, с. 142], что ведет к изоляџии данной группы насемения, препятствует получению ими услуг $[8$, с. 10] и формирует феномен СПИА-диссидентства [9] .

В социально-правовой сфере особую озабоченность вызывают далеко не единичные факты нарушения прав ВИЧ-инфицированных на труд. Современной российской практике трудовых отношений известны случаи, когда работодатели в нарушение закона требуют регулярного медицинского тестирования на ВИЧ-инфекцию; не принимают на работу ВИЧ-инфиџированных и увольняют работников, если они отказываются от сАачи анализов на ВИЧ или оказываются носителями болезни [7, с. 142] .

Трудоправовое положение данной группы работников (потенциальных работников) определяется комплексом актов межжународного и наџионального права. Правовая регламентация труда ВИЧ-инфиџированных граждан решает Авуединую задачу: обеспечить равенство прав таких миџ в трудовых (служебных) отношениях, их защиту в случае Аискриминационных ограничений, но также гарантировать превенџию распространения инфекции при выполнении определенных видов работ. 
Конвенщия МОТ № 111 (1958) «О дискриминаџии в области труда и занятий» [10], принятая до официального открытия ВИЧ / СПИАа, запрешает запрещает Аискриминацию в области труда и занятий; гарантирует равные права в сфере труда мицам, не имеющим специальных ограничений по медицинским показаниям ики при выполнении опредеменных видов работ.

В настоящее время болезнь, вызванная ВИЧ, включена в перечни соџиально значимых заболеваний и заболеваний, представляющих опасность Аля окружающих [11], однако противопоказания Аля выполнения работ такими больными установлены только Аля работников, которые обязаны проходить обязательное освидетельствование на выявление ВИЧ. Согласно ст. 27 Федерального закона от 21 ноября 2011 г. № 323-Ф3 «Об основах охраны здоровья граждан в Российской Федерации, граждане, страдающие заболеваниями, представляющими опасность Аля окружающих, в случаях, предусмотренных законодательством Российской Федерации, обязаны проходить медиџинское обследование и мечение, а также заниматься профилактикой этих заболеваний [12].

В Российской Федераџии обязательному медиџинскому освидетельствованию дмя выявления ВИЧ-инфекщии при поступмении на работу и при периодических медицинских осмотрах подмежат смедующие категории работников:

а) врачи, средний и младший медицинский персонал џентров по профимактике и борьбе со СПИАом, учреждений зАравоохранения, специализированных отделений и структурных подраздемений учреждений зАравоохранения, занятые непосредственным обследованием, диагностикой, кечением, обслуживанием, а также проведением судебно-медиџинской экспертизы и другой работы с миџами, инфицированными вирусом иммунодефицита человека, имеющие с ними непосредственный контакт;

б) врачи, среАний и младший медищинский персонам мабораторий (группы персонала мабораторий), которые осуществцяют обследование насемения на ВИЧ-инфекџию и исследование крови и биологических материалов, полученных от миџ, инфицированных вирусом иммунодефицита чемовека;

в) научные работники, специалисты, служащие и рабочие научно-исслеАовательских учреждений, преАприятий (производств) по изготовлению меАиџинских иммунобиологических препаратов и других организаџий, работа которых связана с материалами, содержащими вирус иммунодефиџита человека $[13 ; 14]$.

Выявление такого заболевания при приеме на работу явмяется законным основанием в заключении трудового договора (полагаем, что и служебного контракта, если работа выполняется государственным или муниципальным служащим). Аица, состоящие в трудовом или служебном правоотношении, в этом случае подмежат увольнению по правицам трудового, служебного законодательства в связи с наличием медицинских противопоказаний (п. 8 ч. 1 ст. 77 Трудового кодекса (ТК) РФ), если невозможно предоставить им Аругую работу [15] .

Постановлением Правительства РФ № 877 перечень конкретных должностей и профессий указанных категорий работников определяется руководителем организаџии [13]. Такой подход вряд ми обеспечит Аолжный уровень 
единства и полный охват всех видов работ, исключающих труд ВИЧ-инфицированных, в каждой конкретной организации.

Согласно ст. 57 ТК РФ работа, связанная с ограничениями (специальными требованиями), домжна соответствовать ТКС и профессиональным стандартам [15]. В федеральном законодательстве и в актах Правительства РФ следовамо бы прямо предусмотреть, что наименования работ должностей, имеющие противопоказания по наличию ВИЧ, Аолжны определяться работодателем на основании ТКС и (или) профессиональных стандартов. В этой части также целесообразно принятие централизованного перечня таких работ, Аолжностей, сформированного на основании существующих Квалификаџионных справочников и профессиональных стандартов.

В целях правовой регламентации труда данной группы граждан Международная организация труда (МОТ) издала СвоА практических правиц по вопросу «ВИЧ / СПИА и сфера труда» (2001) [16]. Аанный документ предусматривает недопущение дискриминации по этому основанию; запрет скрининга с целью исключения миџа из трудового процесса; запрет требовать от соискателей мичных сведений, касающихся ВИЧ; запрет рассматривать ВИЧ-инфекщию как основание для прекращения трудовых отношений. Все эти положения МОТ реализованы в наџиональном законодательстве России. ОАнако анализ международно-правового статуса ВИЧ-инфиџированных гражАан позволяет сделать вывод, что медиџинский признак, в том числе наличие ВИЧ, на межАународном уровне последовательно признается дискриминационным фактором в сфере труда при соответствии деловых качеств работника поручаемой деятельности.

Российское трудовое законодательство (ст. 3 ТК РФ) прямо не содержит указания на то, что состояние здоровья, в том чисме ВИЧ, не может быть основанием ограничения прав и возможностей работника (гражАанина). Если учесть, что далеко не все работодатели хорошо знакомы со специальными правилами о труде ВИЧ-инфиџированных граждан, то есть смысл предусмотреть фактор здоровья в перечне возможных дискриминационных оснований, имея в виду и рассматриваемую категорию граждан с оговоркой, «если иное не преАусмотрено законом».

Первым национальным актом, призванным обеспечить правовую защиту таких ^ищ, стал Закон СССР от 23 апреля 1990 г. № 1447-1 «О профилактике заболевания СПИА» [17]. В соответствии с данным нормативно-правовым актом ВИЧ-инфиџированные граждане получили право на медицинскую и социальную помощь, бесплатный проезА к месту мечения и обратно, бесплатные мекарства при амбулаторном мечении, пенсионное обеспечение. В Законе быма закреплена норма, предусматривающая недопущение увольнения с работы, отказ в приеме на работу, ущемление иных прав и интересов такой категории гражжан. В отношении медицинских работников заражение ВИЧинфекцией в ходе исполнения обязанностей признавалось профессиональным заболеванием.

Постановление Совета Министров СССР от 18 сентября 1990 г. «О мерах по обеспечению соџиальной защищенности миц, зараженных вирусом имму- 
нодефищита человека или больных СПИАом» [18], установимо гарантии для детей до 16 мет, зараженных ВИЧ. Предусматривалось сохранение за одним из родителей в случае расторжения с им трудового договора в связи с уходом за ВИЧ-положительным ребенком в возрасте до 16 мет непрерывного трудового стажа Аля исчисления пособия по временной нетрудоспособности.

Меры социально-правовой защиты вводились и дмя медиков, работающих с этой группой гражАан. Постановление Кабинета министров СССР от 26 апремя 1991 г. «О государственном обязательном страховании работников, занятых оказанием медицинской помощи насемению, проведениями научных исследований по проблемам вирусологии и производством вирусных препаратов, на случай инфицирования вирусом иммунодефицита человека, а также наступцения в связи с этим инвалидности или смерти от СПИАа» [19] предусматривало мьготы и компенсаџии дия медиков, обслуживающих ВИЧинфицированных гражАан.

Основы законодательства об охране здоровья граждан от 22 июля 1993 г. № 5487-I [20] не выдемяли отношения, связанные с ВИЧ / СПИА. Статьи 41 и 42 Основ устанавливали дополнительные гарантии дмя граждан, имеющих социально-значимые заболевания, преАставляющие опасность дмя окружающих.

Конституџия Российской Федераџии от 12 декабря 1993 г. в ч. 3 ст. 55 содержит норму о том, что права и свободы человека и гражданина могут быть ограничены федеральным законом только в той мере, в какой это необходимо в цемях защиты основ конституџионного строя, нравственности, здоровья, прав и законных интересов Аругих миц, обеспечения обороны страны и безопасности государства [21].

Основным федеральным актом, призванным гарантировать права ВИЧ-инфиџированных граждан в соџиальной, в том чисме трудовой сфере, является Федеральный закон от 30 марта 1995 г. № 38-Ф3 «О преАупреждении распространения в Российской Федерации заболевания, вызываемого вирусом иммунодефицита человека (ВИЧ-инфекции)» [22]. Статья 17 этого Закона запрешает увольнение с работы, отказ в приеме на работу, отказ в приеме в организаџии, осуществляющие образовательную деятельность, и медиџинские организации, а также ограничение иных прав и законных интересов ВИЧ-инфицированных только на основании наличия у них ВИЧ-инфекции, равно как и ограничение иных прав и законных интересов чменов семей ВИЧ-инфиџированных, если иное не предусмотрено данным Федеральным законом.

По действующим российским и зарубежным правилам работодатель не вправе требовать от работника сведений о наличии или отсутствии заболевания ВИЧ, кроме случаев, когда это явмяется условием приема на работу. В научной митературе при анализе вопросов приема на работу ВИЧ-инфицированных киџ иниџиируется обязанность гражАан, располагающих информацией о наличии у них ВИЧ-инфекщии, сообщать работодателю указанные данные о заболевании в цемях предупреждения угрозы жизни и здоровью Аругих работников и миџ, их окружающих. Это, считают авторы идеи, смеАует отразить в федеральном законе [23]. С таким предложением, полагаем, можно согласиться, поскольку оно направлено на охрану здоровья насемения 
в целом, а также профикактику распространения ВИЧ-инфекции. При виновном сокрытии такой информаџии действия работника можно оџенивать как змоупотребление правом [24]. ТК РФ не содержат специальных норм, аАресованных данной группе работников; его ст. 69 предусмотрено обязательное предварительное медицинское освидетельствование киц в случаях, предусмотренных ТК РФ и иными федеральными законами. Статья 77 предусматривает возможность расторжения трудового договора при отсутствии работы, перевод на которую необходим по состоянию здоровья работника в соответствии с медицинским закмючением. В соответствии с медиџинским заключением при выявлении противопоказаний, связанных с ВИЧ, работник может быть отстранен или не допушен к работе, обусловленной трудовым договором (ст. 73, 76 ТК РФ).

Аналогично возможен отказ в заключении трудового договора с Аиџом, которому противопоказаны определенные условия труда по состоянию здоровья или состояние здоровья которого представмяет опасность дмя окружающих при выполнении ими определенных трудовых обязанностей, Аибо Аиџом, отказавшимся пройти предварительное обязательное медиџинское освидетельствование. Очевидно, что при этом имеется в виду и наличие ВИЧ-инфекции.

В современной российской судебной практике практически нет дел, связанных с обжалованием незаконного увольнения ВИЧ-инфиџированных работников. ОАнако единичные примеры таких увольнений рассмотрены на уровне межАународного правосудия и права уволенных работников признаны нарушенными [25].

Наряду с федеральными правилами правовое положение ВИЧ-инфицированных граждан в настоящее время определяется и актами субъектов РФ. ОАнако, следуя разграничению предметов ведения Российской Федераџии и субъектов РФ, предусмотренному ст. 6 ТК РФ, труа ВИЧ-инфиџированных, явмяющихся, по сути, отдельными категориями работников, не может специально регулироваться актами краев, областей, республик. В региональном законодательстве и распорядительных актах руководителей субъектов РФ, поцагаем, излишне Аубцируются нормы закона 1995 г. № 38-Ф3, а также меры Аополнительной соџиальной защиты и самих заболевших гражАан, и членов их семей [26-29].

В целях возможного совершенствования норм трудового права России, определяющих статус ВИЧ-инфицированных гражАан, имеет смысл ознакомиться с опытом такого регулирования за рубежом. Так, Закон Румынии № 137/2000 о предотвращении и ответственности за июбые виды дискриминаџии [30] содержит понятие «преследования миџ из небкагополучных категорий населения». Имеются в виду категории населения, которые оказались в менее благоприятном положкении по сравнению с большинством граждан в силу своего происхождения, миџа, столкнувшиеся с неприятием их обществом и маргинализаџией в силу особых жизненных обстоятельств, включая инфиџирование ВИЧ / СПИАом. Запрещается дискриминаџия указанных групп насемения в сфере труда.

Заслуживает внимания и Закон Вемикобритании о дискриминации инвали- 
дов 1995 г. [31], запрещающий дискриминащию работников или соискателей в связи с инвалидностью во всех обцастях трудовых отношений; под опредемение инвалидности подпадает и ВИЧ / СПИА. ОАнако Закон охватывает СПИА мишь на симптоматической стадии заболевания, то есть инвалидом будет считаться работник, у которого ВИЧ перешел в более тяжелую стадию СПИАа с Аальнейшим ухудшением здоровья. Закон обязывает работодателя принимать меры к сохранению трудовых отношений с ВИЧ-инфиџированным работником. Аля реализаџии данной обязанности работодатель должен переоборудовать рабочие помешения, внеАрять гибкий рабочий график, предоставлять дополнительное время на мечение, освобождать работников от некоторых трудовых обязанностей, переводить на Аругую должность. Предусмотрена ответственность работодателя за дискриминацию работников даже в тех случаях, когда факт дискриминации произошел без их ведома или одобрения, если только работодатель не предоставит достаточных свидетельств того, что он предпринимал все возможные меры Аля предотвращения дискриминации.

В Законе США 1990 г. об американцах-инвалидах [32] ВИЧ-инфиџированный работник рассматривался как переквалифиџированный, то есть способный выполнять свои трудовые обязанности при изменениях функции и условий труда. Имеется и Аругой пример из практики США: при поступлении на работу у гражданина была выявлена ВИЧ-инфекция, но он был трудоустроен, к тому же работодатель выпцачивац ему ежемесячное пособие на соответствующее мечение [33]. Подобные нормы в российском законодательстве отсутствуют.

Сравнение указанных зарубежных правиц с нормами российского закона № 38-Ф3, ограничивающегося общими фразами о запрете отказывать в приеме на работу и увольнять по мотивам наличия ВИЧ, не в пользу последнего. Безусловно, необходимо не просто запретить дискриминаџионное увольнение, но прежде всего ясно и конкретно определить порядок действий работодателя в отношении работника, заболевшего ВИЧ / СПИА. Эти действия не Аолжны исчерпываться общим правимом о предложении Аругой работы, но вкмючать меры по профессиональному обучению дмя выполнения Аругой работы, пересмотру условий труда, позволяющих сохранить занятость и Аругие меры, аналогичные правилам стран Запада. Вряд $и$ стоит соответствующие положения включать в ТК РФ, предлагаемыми гарантиями достаточно дополнить статью 17 Федерального закона № 38-Ф3 [22].

\section{Библиографический список}

1. Мороз О. Группа риска. М., 1990.

2. Федеральная служба по надзору в сфере защиты прав потребителей и благополучия человека. Инфекционная заболеваемость в Российской Федерации за январь - июнь 2018 г. URL: http://rospotrebnadzor.ru/activites/statisticalmaterials/statictic_details.php?ELEMENT_ID=10419

3. Федеральная служба государственной статистики. Социально-экономическое положение России. Январь - апрель 2018 г. URL: http://http://www.gks.ru/free_doc/doc_2018/social/osn04-2018.pdf

4. Дзарасов М., Рущанов А., Трифонов Д. Трансатлантические партнеры против СПИДа. M., 2005. 
5. Стигма и ВИЧ: определение. URL: http://www.aids.ru/aids/stigmadef.shtml

6. Луговая E.A. Современная российская проблематика стигматизации и дискриминации ВИЧ-инфицированных людей // Вестник Поволжской академии государственной службы. 2007. № 13. С. $159-163$.

7. Явон С.В. ВИЧ-инфицированные: дискриминация и нарушение прав // Социологические исследования. 2016. № 6 (386). С. 142-144.

8. Концептуальная основа и основополагающие принципы деятельности: Стигма и дискриминация в связи с ВИЧ / СПИДом. Объединенная программа ООН по ВИЧ / СПИДу. Женева, 2002.

9. Смерть за миф. Как ВИЧ-диссиденты зарабатывают на вере больных. URL: http://spid. center/ru/articles $/ 458$

10. О дискриминации в области труда и занятий: Конвенция Международной организации труда № 111 (Женева, 25 июня 1958 г.) // Ведомости ВС СССР. 1961. № 44. Ст. 448.

11. Об утверждении перечня социально значимых заболеваний и перечня заболеваний, представляющих опасность для окружающих: постановление Правительства РФ от 1 дек. 2004 г. № 715 // С3 РФ. 2004. № 49. Ст. 4916.

12. Об основах охраны здоровья граждан в Российской Федерации: Федер. закон от 21 нояб. 2011 г. № 323-Ф3 // СЗ РФ. 2011. № 48. Ст. 6724.

13. Об утверждении Перечня работников отдельных профессий, производств, предприятий, учреждений и организаций, которые проходят обязательное медицинское освидетельствование для выявления ВИЧ-инфекции при проведении обязательных предварительных при поступлении на работу и периодических медицинских осмотров: постановление Правительства РФ от 4 сент. 1995 г. // СЗ РФ. 1995. № 37. Ст. 3624.

14. Методические рекомендации о проведении обследования на ВИЧ-инфекцию, утв. Минздравсоцразвития РФ 6 авг. 2007 г. № 5950-РХ. [Электронный ресурс]. Доступ из СПС «КонсультантПлюс».

15. Трудовой кодекс Российской Федерации от 30 дек. 2001 г. № 197-Ф3 с изм. от 3 авг. 2018 г. № 315-Ф3 // С3 РФ. 2002. № 1 (часть I). Ст. 3.

16. Свод практических правил МОТ по вопросу «ВИЧ / СПИД и сфера труда» (2001). URL: http://www.ilo.org/wcmsp5/groups/public/---ro-geneva/---sro-moscow/documents/publication/wcms_247908.pdf

17. О профилактике заболевания СПИД: Закон СССР от 23 апр. 1990 г. № 1477-1 (утратил силу) // Свод законов СССР. 1990. Т. 3.

18. О мерах по обеспечению социальной защищенности лиц, зараженных вирусом иммунодефицита человека или больных СПИДом: постановление Совета Министров СССР от 18 сент. 1990 г. URL: http://garant.ru

19. О государственном обязательном страховании работников, занятых оказанием медицинской помощи населению, проведениями научных исследований по проблемам вирусологии и производством вирусных препаратов, на случай инфицирования вирусом иммунодефицита человека, а также наступления в связи с этим инвалидности или смерти от СПИДа: постановление Кабинета министров СССР от 26 апр. 1991 г. URL: http://garant.ru

20. Основы законодательства об охране здоровья граждан от 22 июля 1993 г. № 5487-I (утратили силу). URL: http://garant.ru

21. Конституция Российской Федерации // СЗ РФ. 2014. № 31. Ст. 4398.

22. О предупреждении распространения в Российской Федерации заболевания, вызываемого вирусом иммунодефицита человека (ВИЧ-инфекции): Федер. закон от 30 марта 1995 г. № 38-Ф3 (с изм. от 23 мая 2016 г. № 149-Ф3) // СЗ РФ. 1995. № 14. Ст. 1212.

23. Болдырев Р.О., Минкина Н.И. Проблема определения трудоправового статуса ВИЧ-инфицированных лиц // Медицинское право. 2016. № 5. С. 36-39.

24. Офман Е.М., Станскова У.М. Противодействие злоупотреблению правом: зарубежный 
опыт и трудовое законодательство Российской Федерации // Трудовое право в России и за рубежом. 2011. № 1. С. 57-62.

25. Постановление ЕСПЧ от 3 окт. 2013 г. по делу «ІВ. (І.В.) против Греции» (жалоба № 552/10). По делу обжалуется увольнение работника, страдающего от ВИЧ-инфекции, вследствие давления со стороны коллег. По делу допущено нарушение требований статьи 14 Конвенции о защите прав человека и основных свобод // Бюллетень Европейского Суда по правам человека. 2014. № 2.

26. О предупреждении распространения на территории Республики Башкортостан заболевания, вызываемого вирусом иммунодефицита человека (ВИЧ-инфекции): Закон Республики Башкортостан от 21 дек. 1998 г. № 209-з (с изм. от 6 дек. 2016 г. № 441-3) // Ведомости Государственного Собрания, Президента и Кабинета министров Республики Башкортостан. 1999. № 7 (91). Ст. 409.

27. О предупреждении распространения в Краснодарском крае заболевания, вызываемого вирусом иммунодефицита человека (ВИЧ-инфекции): Закон Краснодарского края от 2 авг. 1999 г. № 201-КЗ (с изм. от 11 марта 2016 г. № 3350-К3). URL: http://garant.ru

28. О предупреждении распространения на территории города Москвы заболевания, вызываемого вирусом иммунодефицита человека (ВИЧ-инфекции): Закон г. Москвы от 26 мая 2010 г. № 21. URL: http://garant.ru

29. Об устранении нарушений Федерального закона «О предупреждении распространения в Российской Федерации заболевания, вызываемого вирусом иммунодефицита человека (ВИЧ-инфекции)» на территории г. Иркутска»: постановление главного государственного санитарного врача по г. Иркутску от 3 апр. 2001 г. № 3. URL: http://garant.ru

30. Комитет по ликвидации расовой дискриминации. 16-19 периодические доклады, подлежащие представлению в 2007 г. Румыния. 29 июля 2008. URL: https://www.refworld.org.ru/ $\operatorname{docid} / 4 \mathrm{c} 85 \mathrm{f} 2852 . \mathrm{html}$

31. Disability Discrimination Act 1995. The Public Service Vehicles (Conduct of Drivers, Inspectors, Conductors and Passengers) (Amendment) Regulations 2002 Guidance. URL: http://assets.publishing.service.gov.uk/government/uploads/attachment_data/file/3260/sstopublicevehicle5990.pdf

32. Об инвалидах: Закон США от 26 июля 1990 г. URL: http://pravo-med.ru/articles/403/

33. Ломакин A. Злоупотребление правом со стороны работника при увольнении по инициативе работодателя // Трудовое право. 2012. № 11. С. 73-74. 